\title{
Post-stroke physical rehabilitation in a Romanian Geriatric Department
}

\author{
ANA CAPISIZU ${ }^{1,2}$, ANDREEA ZAMFIRESCU ${ }^{2}$, ANCA MIRSU-PAUN ${ }^{1}$, GELU ONOSE ${ }^{1,3}$, \\ SORINA MARIA AURELIAN ${ }^{1,2}$ \\ ${ }^{1}$ University of Medicine and Pharmacy "Carol Davila" Romania \\ ${ }^{2}$ Geriatric Department-Chronic Disease Hospital "St.Luca” Bucharest, Romania \\ 3,'Bagdasar-Arseni" Emergency Clinical Hospital, Bucharest, Romania
}

\begin{abstract}
Aim: Rehabilitation after stroke help patients to become more independent as possible and to achieve a better quality of life. Exercise repeated encourages brain plasticity and helps reduce disability. Stroke is common in the elderly population and the leading cause of disability.
\end{abstract}

Methods: It is a prospective-cross-sectional study for 1 year in Geriatric Department "St.Luca" Bucharest. 119 inpatients $(62,2 \%$ female, mean-age 79.03 \pm 7.13$)$ with one first unilateral stroke and no severe cognitive impairment were enrolled. Functionality was assessed by Tinetti-dynamic-Scale( Romanian version), Barthel-Index and Reisberg-Scale. Data were collected twice, at inclusion(T1) and after 1 month(T2) of daily physical activity (practicing isolated movements, repeatedly changing from one kind of movement to another, rehearsing complex movements that require a great deal of coordination and balance, such as walking up or down stairs or moving safely between obstacles). Statistical multivariate analyses were made by SPSS 22.0.

Results: Paired sample t-tests were conducted to examine group differences. Improvement in scores for all three assessment instruments were obtained: Tinetti $\mathrm{t}(36)=3.78, \mathrm{p}<0.0001$, scores decreased 1,40 units; Barthel $\mathrm{t}(36)=11.79$, $\mathrm{p}<0.0001$, scores increased 7.16 units; and Reisberg $\mathrm{t}(36)=-7.61, \mathrm{p}<$ 0.0001 , scores decreased 0.54 units.

Conclusion: KT had a positive impact on functional capacity after one month of treatment. Patients with KT improved on Reisberg and Tinetti scales statistically significant. Physical therapists and physicians establish exercise programs, compensatory strategies to reduce the effect of remaining deficits.

Key words: post-stroke elderly, physical rehabilitation, functionality

References:

1. Gale EA. The myth of the metabolic syndrome. Diabetologia. 2005; 48: 1679-83. 3.

2. Kahn R, Buse J, Ferrannini E, et al. The metabolic syndrome: time for a critical appraisal. Joint statement from the American Diabetes Associa-tion and the European Association for the Study of Diabetes. Diabetolo-gia. 2005; 48 : 1684-99

3. Alberti KG, Zimmet P, Shaw J, et al. The metabolic syndrome--a new worldwide definition. Lancet. 2005; 366: 1059-62

4. Adamopoulos D, Vyssoulis G, Karpanou E, Kyvelou SM, Argacha JF, Cokkinos D et al. Environmental determinants of blood pressure, arterial stiffness, and central hemodynamics." Journal of Hypertension, 2010; 28(5), 903-9

5. Ikonomidis I, Ntai K, Kadoglou NPE, Papadakis I, Koukoulis C, Tritakis B, Trivilou P et al. The evaluation of pulse wave velocity using Arteriograph and Complior apparatus across different cardiovascular-related diseases. Eur Heart J (2013) 34 (suppl 1):doi:10.1093/eurheartj/eht307.P356

Conflicts of interest: none. 